\title{
Control Strategies for Induction Motors in Railway Traction Applications
}

\author{
Ahmed Fathy Abouzeid ${ }^{1}{ }^{\circledR}$, Juan Manuel Guerrero ${ }^{1} @$, Aitor Endemaño ${ }^{2}$, Iker Muniategui ${ }^{2}$, \\ David Ortega ${ }^{2}$, Igor Larrazabal ${ }^{2}$ and Fernando Briz ${ }^{1, *(1)}$ \\ 1 Electrical, Electronic, Computers and Systems Engineering, University of Oviedo, 3204 Oviedo, Spain; \\ abouzeidahmed@uniovi.es (A.F.A.); guerrero@uniovi.es (J.M.G.) \\ 2 Ingeteam Power Technology S.A.-Traction, 48170 Zamudio, Spain; aitor.endemano@ingeteam.com (A.E.); \\ iker.muniategui@ingeteam.com (I.M.); David.Ortega@ingeteam.com (D.O.); \\ igor.larrazabal@ingeteam.com (I.L.) \\ * Correspondence: fbriz@uniovi.es
}

Received: 30 December 2019; Accepted: 3 February 2020; Published: 6 February 2020

check for updates

\begin{abstract}
This paper analyzes control strategies for induction motors in railway applications. The paper will focus on drives operating with a low switching to fundamental frequency ratio and in the overmodulation region or six-step operation, as these are the most challenging cases. Modulation methods, efficient modes of operation of the drive and the implications for its dynamic performance, and machine design will also be discussed. Extensive simulation results, as well as experimental results, obtained from a railway traction drive, are provided.
\end{abstract}

Keywords: railway traction drives; induction motor drives; high-speed drives; maximum torque per ampere; overmodulation and six-step operation

\section{Introduction}

Despite being one of the most energy-efficient means for mass transportation (see Figure 1) [1], there is pressure to develop a more efficient, reliable, cheap, and compact railway traction system, which should be achieved without compromising customer satisfaction.

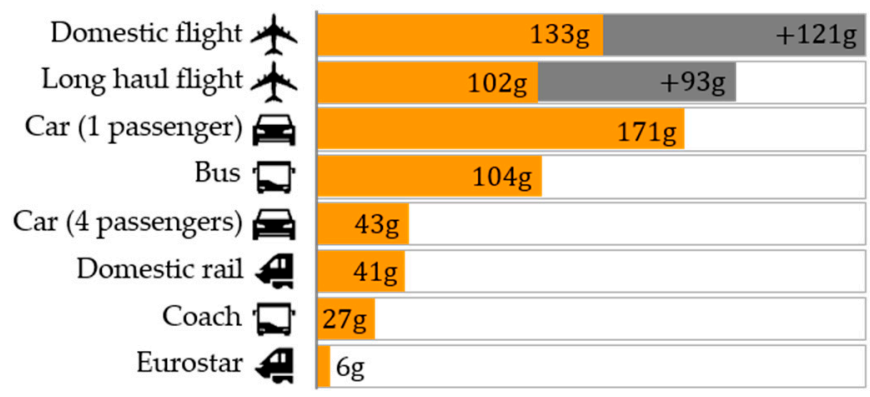

Figure 1. Emissions per passenger per km from different modes of transport. From the UK Department for Business, Energy and Industrial Strategy 2019 Government Greenhouse Gas Conversion Factors [1].

Three-phase induction motors (IMs) were adopted in the 1990s for traction systems in railways replacing DC machines [2] due to their increased robustness and reduced cost and maintenance requirements. In addition, precise control of the IM torque/speed is perfectly possible thanks to the development of new power devices and digital signal processors, combined with the advances in AC-driven control methods. Furthermore, the inherent slip of IM allows multiple motors to be fed from a single inverter, even if they rotate at different speeds due to differences in wheel diameters. As a 
result, the voltage-source inverter-fed IM drive (VSI-IM) is currently the preferred option in traction systems for railways [3]. While Permanent Magnet Synchronous Machines (PMSM) have also been considered and can be found in several traction systems, cost and reliability concerns intrinsic to this type of machine, mainly due to magnets, have so far prevented their widespread use [4].

Rolling stock can be classified according to the power level of the traction system, ranging from several tens of kW for Light Rail systems, to several MW for High-Speed Trains (HST) and Heavy Rail Locomotives [5]. Traction systems can be concentrated or distributed. In concentrated systems, one or more locomotives pull unmotorized coaches. On the contrary, distributed traction systems use Electric Multiple Units (EMU), i.e., self-propelled carriages. Both options have advantages and disadvantages. EMUs can provide a superior performance in terms of the acceleration and deceleration times, adhesion effort, and transport capacity. However, passenger comfort, maintenance, and pantograph operation can be compromised in this case [6,7]. For the case of HST, European manufacturers have predominantly adopted the concentrated traction option, while the distributed option has been preferred by Japanese manufacturers [8].

The two main elements in a traction system are the electric motor and the inverter. The development of a cost-effective traction system for a given application involves a complex, iterative process to decide the number of traction motors, motor size, inverter rated power, cooling system, etc. Once the physical elements of the traction system have been defined, the control and modulation strategies need to be defined. Additionally, in this case, a complex iterative process can be required as the traction system must comply with a number of requirements. These include those imposed by the desired train performance (e.g., torque-speed characteristic, maximum torque and speed, acceleration/deceleration times, etc.), electric drive performance (e.g., machine and inverter efficiency, temperature limits, maximum torque ripple, etc.), existing standards (e.g., electromagnetic interference, acoustic noise, etc.), and so on. However, these targets will often be in conflict. The reduction of inverter losses requires low switching frequencies, which in turn result in higher losses and large torque pulsations in the motor, and can also compromise the dynamic response or even the stability of the drive. Especially challenging is the operation of the traction drive at high speeds. The large back-electromotive force, in this case, forces the inverter to operate in the overmodulation region, including square-wave modes. The control operates in this case with a reduced (or even no) voltage margin and large distortions in the currents, which can further deteriorate the drive performance.

Figure 2 shows a schematic representation of the main blocks involved in the operation of a traction drive. The drive will normally receive a torque command coming from outer control loops (e.g., the train driver or speed control loop). From the torque command and in the operating condition of the machine, a flux command is derived; different criteria can be followed for this purpose, as shown in Figure 2. Torque and flux are controlled by the inner control loops; a number of solutions are available for this purpose. Inner control loops will provide the voltage command to the Voltage Source Inverter (VSI) feeding the machine, with selection of the modulation method being of the highest importance.

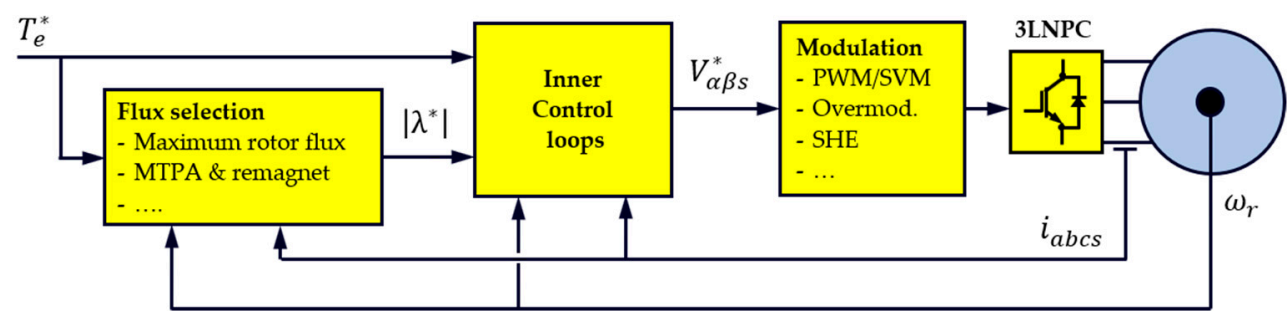

Figure 2. Main blocks of a traction drive.

This paper presents a review of the different aspects involved in the control of IM motor drives for railway applications. Section 2 reviews the IM motor model, including a discussion on the machine characteristics. Section 3 discusses control strategies, with a special focus on their suitability for use 
at high speed and low switching frequencies, as this is the most frequent and challenging mode of operation for traction drives. Modulation is discussed in Section 4. Section 5 discusses efficient modes of operation and remagnetization strategies. Sections 6 and 7 provide simulation and experimental results, respectively. Section 8 summarizes the conclusions.

\section{Induction Motor Model and Machine Characteristics}

\subsection{Induction Motor Model}

Complex vectors allow a compact, insightful dynamic representation of the physical effects occurring in AC machines, i.e., the relationships among electromagnetic variables (voltages, currents, and fluxes) and shaft variables (torque and speed) [9]. Equations (1)-(4) show the electromagnetic complex vector equations describing the squirrel cage induction machine in a synchronous reference frame rotating at the flux angular frequency $\omega_{e}$, where $v_{d q s}$ denotes the stator voltage; $i_{d q s}$ and $i_{d q r}$ are the stator and rotor currents, respectively; $\lambda_{d q s}$ and $\lambda_{d q r}$ represent the stator and rotor fluxes, respectively; $R_{s}$ and $R_{r}$ are the stator and rotor resistances, respectively; $L_{s}, L_{r}$, and $L_{m}$ are the stator, rotor, and mutual inductances, respectively; $\omega_{r}$ is the rotor angular speed in electrical units; and $p$ is the derivative operator.

$$
\begin{gathered}
v_{d q s}=R_{s} i_{d q s}+p \lambda_{d q s}+j \omega_{e} \lambda_{d q s} \\
0=R_{r} i_{d q r}+p \lambda_{d q r}+j\left(\omega_{e}-\omega_{r}\right) \lambda_{d q r} \\
\lambda_{d q s}=L_{s} i_{d q s}+L_{m} i_{d q r} \\
\lambda_{d q r}=L_{m} i_{d q s}+L_{r} i_{d q r}
\end{gathered}
$$

The electromagnetic torque $T_{e}$ can be expressed as the cross product of stator and rotor currents (5). $P$ is the number of pole-pairs, and " $I m$ " and " $~ f$ " denote the imaginary part and complex conjugate, respectively.

$$
T_{e}=\frac{3}{2} P L_{m} \operatorname{Im}\left\{i_{d q s} i_{d q r}^{\ddagger}\right\}
$$

Equations (1)-(4) can be particularized for the case when the d-axis is aligned with the rotor flux, i.e., $\lambda_{d q r}=\lambda_{d r}=\lambda_{r}$, which is the base of rotor field-oriented control (RFOC). The stator voltage equation in scalar form is, in this case (6), the rotor flux dynamics being given by (7), where $\tau_{r}$ is the rotor time constant and $\sigma$ is the leakage factor.

$$
\left.\begin{array}{c}
v_{d s}=R_{s} i_{d s}+\sigma L_{s} p i_{d s}-\omega_{e} \sigma L_{s} i_{q s}+\frac{L_{m}}{L_{r}} p \lambda_{r} \\
v_{q s}=R_{s} i_{q s}+\sigma L_{s} p i_{q s}+\omega_{e} \sigma L_{s} i_{d s}+\omega_{e} \frac{L_{m}}{L_{r}} \lambda_{r}
\end{array}\right\} \begin{gathered}
\tau_{r} \frac{d \lambda_{r}}{d t}+\lambda_{r}=L_{m} i_{d s} ; \tau_{r}=\frac{L_{r}}{R_{r}} ; \sigma=1-\frac{L_{m}^{2}}{L_{s} L_{r}}
\end{gathered}
$$

The torque Equation (5) can be rewritten as (8) in this case. Other forms of the torque equation can be obtained by combining (2)-(4) and (5) and will be the basis of different control strategies, as will be discussed in further sections.

$$
T_{e}=\frac{3}{2} P \frac{L_{m}}{L_{r}} \lambda_{r} i_{q s}
$$




\subsection{Machine Characteristics}

Traction drives commonly receive a torque command from an outer control loop, which is responsible for speed control. The maximum torque that can be produced at a given speed will essentially depend on the current limits of the machine and power converter (due to losses) and on the maximum flux, which is limited by saturation and the available DC link voltage. For most IM designs, the maximum voltage and field weakening occur at the same speed, i.e., field weakening is a direct consequence of reaching the voltage limit. This is shown schematically in Figure 3 (continuous line case). For rotor speeds $\omega_{r}<\omega_{1}$, the machine operates with a rated flux and current, with the voltage increasing proportionally to the rotor speed, mainly due to the back-emf. If $\omega_{r}>\omega_{1}$, the flux, and consequently torque, must be decreased. The current (Figure 3b) can still be maintained at its rated value until the machine enters field-weakening region II (not shown in the figure) [10]. Therefore, for the machine denoted as conventional in Figure 3, region (1) corresponds to a constant torque operation, while regions (2)+(3) have constant power.

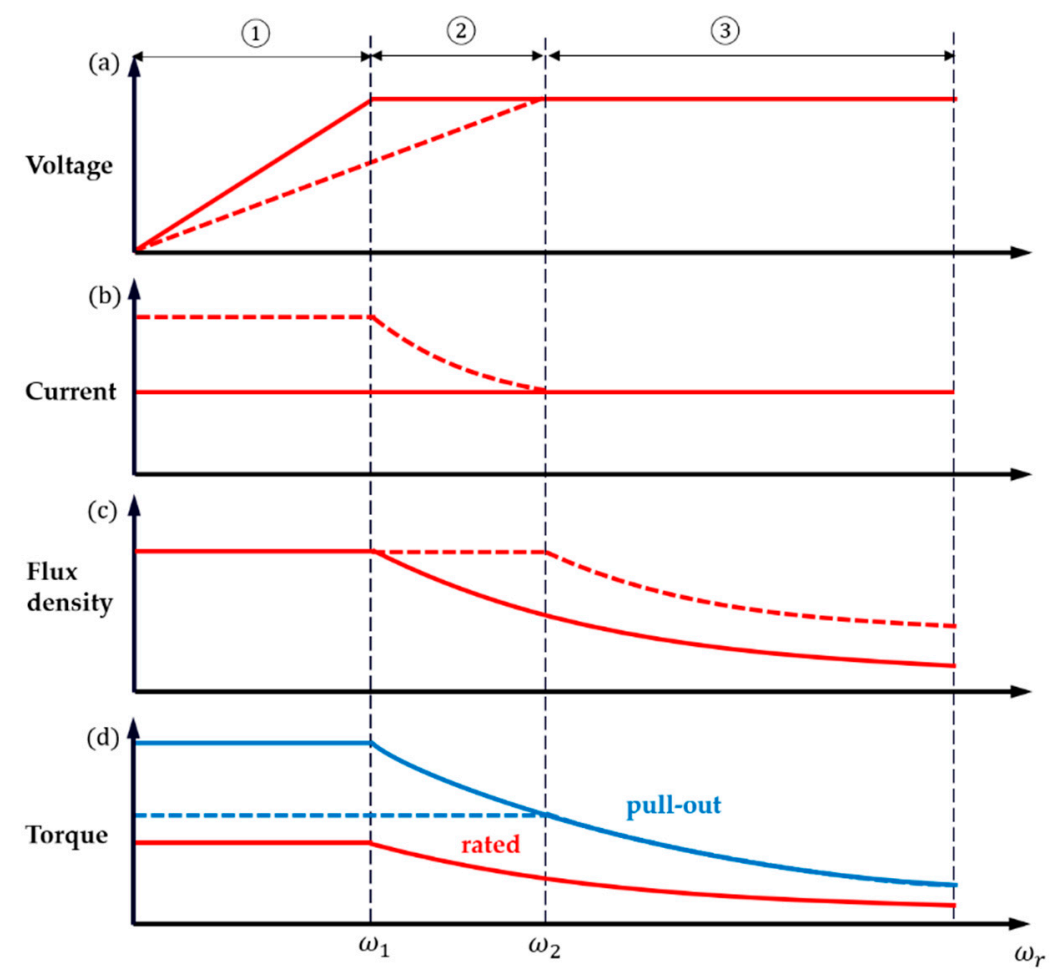

Figure 3. Conventional (-) and extended full flux range (--) induction motor (IM) design behavior: (a) Stator voltage magnitude; (b) Stator current magnitude; (c) Flux density; (d) Electromagnetic torque (rated\&pull-out). Both machines are designed to provide the same torque vs. speed characteristic and have the same voltage limit.

IM designs for railway traction are often aimed at reducing the size of the machine, which can be desirable or even imperative due to room constraints. For this purpose, the voltage characteristic of the conventional design in Figure 3 can be modified by rewinding the stator, varying the number of turns, and gauging the wire $[10,11]$. If the modification is made such that $N_{2}<N_{1}$, with $N_{1}$ and $N_{2}$ being the number of turns for the conventional and modified designs, respectively, and the active conductor area in each stator slot remaining unchanged, i.e., $N_{1} \cdot S_{1}=N_{2} \cdot S_{2}$, and $S_{1}$ and $S_{2}$ being the area of the conductor for the conventional and modified designs, respectively, both machines should be able to produce the same amount of torque, as the total current circulating within the stator slots and the rest of the machine dimensions are the same in both cases [11]. Since the number of turns has been reduced, the voltage vs. speed characteristic is also modified. As seen in Figure 3a (dashed line), for $\omega_{r}=\omega_{1}$, 
the machine is far from its voltage limit. It can also be observed that for $\omega_{r}<\omega_{1}$, the current of the modified machine design is $N_{1} / N_{2}$ larger than for the conventional design. This does not imply an increase of joule losses, as the wire in the modified design is thicker, and the current density is the same in both cases. Since, at $\omega_{r}=\omega_{1}$, the modified machine operates well below its voltage limit, there is no need to decrease the flux at this point; instead, the nominal air gap flux density can be maintained until $\omega_{r}=\omega_{2}$ (region (2) in Figure 3), i.e., the full flux range is extended. The fact that the flux weakening region is reduced while the torque characteristic remains unchanged enables a reduction of the stator current for $\omega_{r}>\omega_{1}$, as can be readily deduced from (8). Consequently, assuming that the dimensions of the machine do not change, the extended full flux range design in Figure 3 would allow a significant decrease of the current density in regions (2) and (3) (i.e., at high train speeds) and consequently of Joule losses, i.e., would be more efficient compared to the conventional design.

However, the design with an extended full flux range offers other possibilities. The torque of an IM can be written as (9), where $V_{\text {rotor }}$ is the active volume of the rotor, $J$ is the stator surface current density, $B$ is the air gap flux density, $\varnothing$ is the angle between $J$ and $B$ vectors, and $k_{1}$ is a constant which depends on the machine winding design [11].

$$
T_{e}=k_{1} \cdot V_{\text {rotor }} \cdot J \cdot B \cdot \cos (\varnothing)
$$

As the extended full flux range design provides higher flux densities at high speeds and the current density $J$ remains constant, it is possible to reduce the volume of the rotor, and consequently the size of the machine, without affecting the torque production capability, i.e., the extended full flux design in Figure 3 will be smaller.

It must be noted, however, that redesigning the machine brings drawbacks that must also be considered. First, the size of the inverter is increased, as the current that the semiconductors must handle is increased by a factor of $N_{1} / N_{2}$, while the voltage and power remain unaffected. However, this penalty is not so relevant nowadays thanks to the latest developments in power devices [10]. Second, the pull-out torque in the low-speed region is significantly decreased, as shown in Figure 3d [11], which must be considered to guarantee that the machine meets the application requirements.

\section{Overview of Control Methods for Three-Phase Induction Machines}

This section discusses control strategies for IMs in railway applications. The drives must be able to perform properly from zero to relatively high rotational frequencies. On the other hand, the switching frequencies are often limited to several hundred $\mathrm{Hz}$ due to the switching losses of high-power semiconductor devices. At low rotational frequencies, the switching to fundamental frequency ratio is still relatively large and the inverter will operate far from its voltage limit. On the contrary, operation at high speeds is characterized by a reduced switching to fundamental frequency ratio and a reduced (or even inexistent) voltage margin in the inverter. Due to this, both control and modulation strategies are often dynamically modified, depending on the IM speed. The following discussion will primarily focus on the most challenging high-speed case.

Control methods for IMs can be classified into scalar and vector types, as shown in Figure 4. Scalar methods are derived from the machine equivalent circuit in a steady-state. Consequently, they can operate properly in applications in which fast changes in the operating conditions of the machine (torque, speed, flux .... ) are not required. On the contrary, vector control methods are based on the dynamic equations of the machine, which, combined with proper control loops, allow the machine's torque capabilities to be fully exploited, without surpassing machine or power converter limits. Both types of methods are briefly discussed in the following. It must be noted, however, that the borderline between scalar- and vector-based methods is sometimes blurred, as there have been several proposals to enhance the dynamic response of scalar methods by adding control loops based on dynamic models. 


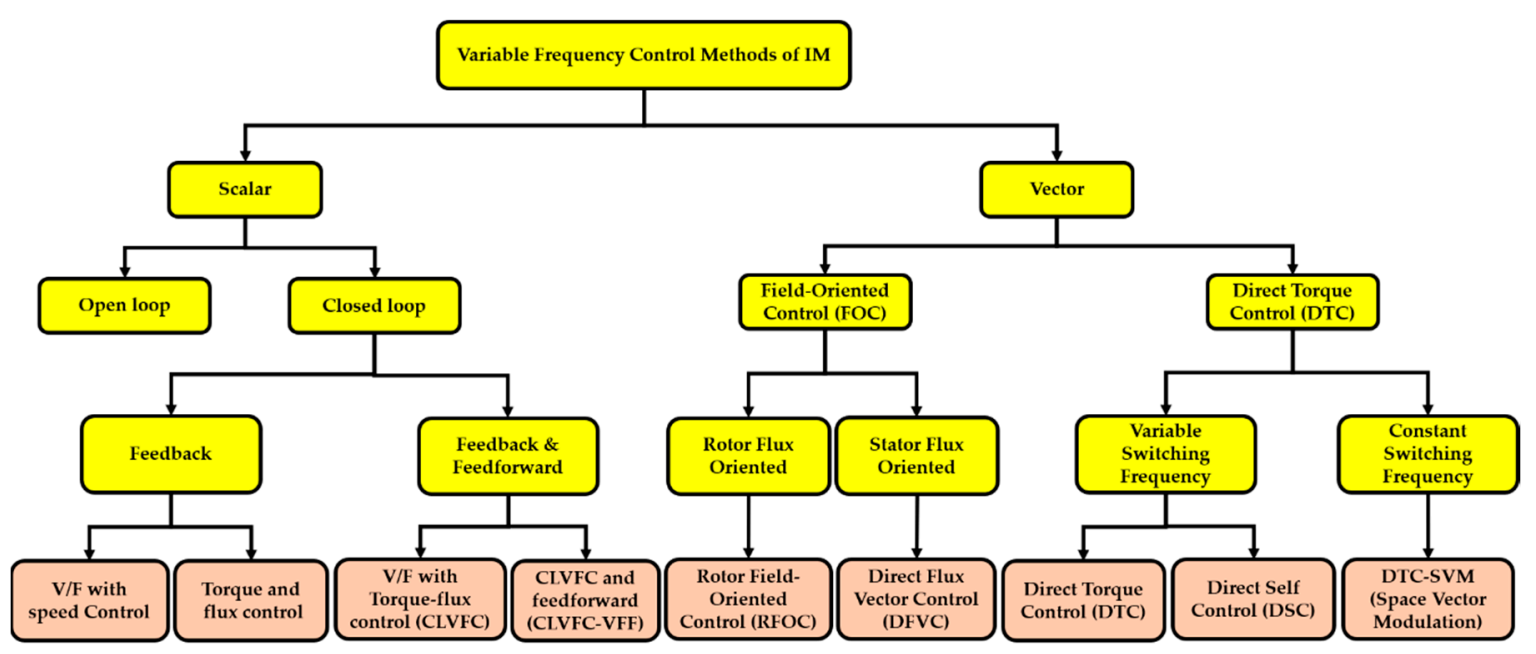

Figure 4. Control methods for IMs.

\subsection{Scalar-Based Control}

\subsubsection{Open-loop V/F}

Open-loop V/F varies the stator voltage magnitude proportional to the frequency. This results in an (almost) constant flux. While simple, $\mathrm{V} / \mathrm{F}$ control has some relevant limitations. The rotor speed is not precisely controlled due to slip. Additionally, an incorrect voltage to frequency ratio, voltage drop in the stator resistance, variations of the DC link voltage feeding the inverter, etc., will result in incorrect flux levels, eventually modifying the operating point of the machine from the desired value.

\subsubsection{V/F with Feedback Control}

Closed-loop speed control with slip regulation (Figure 5) has been widely used in IM traction drives [12]. Speed error generates the slip command $\omega_{s l}^{*}$ through a Proportional-Integrator (PI) controller, which, when added to the measured speed, provides the angular frequency of the stator voltage $\omega_{e}^{*}$.

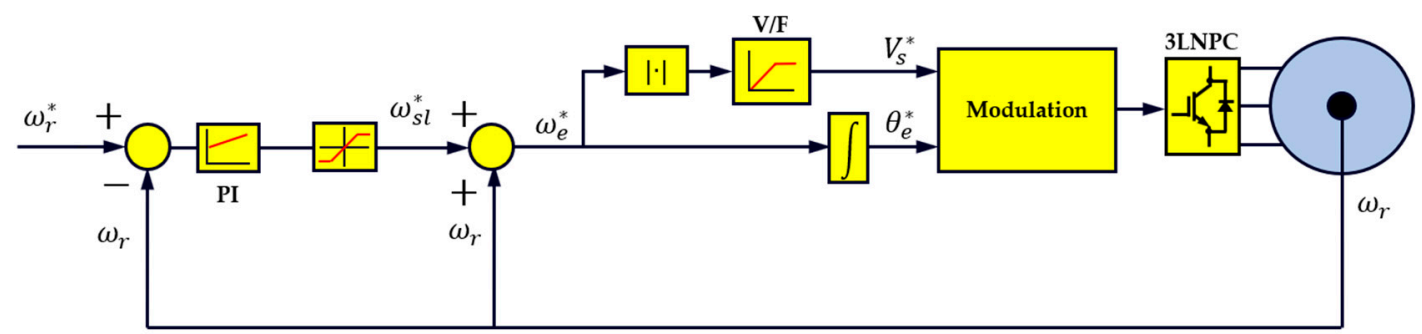

Figure 5. V/F with speed control scheme.

Flux and torque control loops can be used instead of the V/F ratio to obtain the desired stator voltage magnitude and angle (Figure 6). Torque and flux can be estimated from the (commanded) stator voltages and the (measured) stator currents using the voltage model (10); "“" indicates estimated variables/parameters. The pure integrator in (10) is replaced in practice by a first-order system to avoid the drift problems derived from the integrator infinite gain at DC [13]. The torque is obtained using (11).

$$
\begin{gathered}
\hat{\lambda}_{\alpha \beta s}=\int\left(V_{\alpha \beta s}^{*}-\hat{R}_{s} i_{\alpha \beta s}\right) d t \\
\hat{T}_{e}=\frac{3}{2} P\left(\hat{\lambda}_{\alpha s} i_{\beta s}-\hat{\lambda}_{\beta s} i_{\alpha s}\right)
\end{gathered}
$$




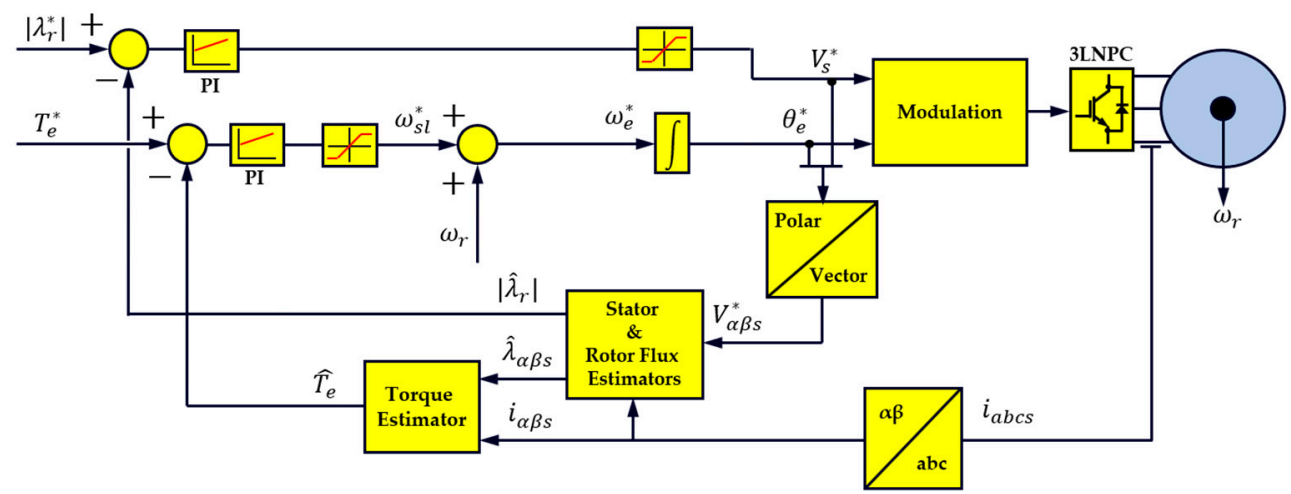

Figure 6. Torque-flux scalar control scheme.

The methods in Figures 5 and 6 are relatively simple to implement, with the second enabling precise control of the machine's operating point in a steady-state. A further advantage of scalar methods is that operation near or at the inverter voltage limit is relatively easy to achieve. However, the fact that coupling between flux and torque is not considered for the control design requires a very slow dynamic response to avoid over currents and torque pulsations.

\subsubsection{Torque/Flux Scalar Control with Feedforward}

The dynamic response of the closed-loop V/F control scheme in Figure 6 can be enhanced by adding two feedforward terms, as can be seen in Figure 7. The first uses the desired V/F characteristic to provide the base value of the stator voltage magnitude $V_{s v f}^{*}$, with the rotor flux regulator providing the incremental voltage required to track the desired rotor flux with no error. The second provides the base value for the slip $\omega_{s l_{-} f}^{*}$, which is obtained from the desired torque and the estimated rotor flux using (12). The torque regulator corrects the slip so that the desired torque is followed with no error.

$$
\omega_{s l_{-} f f}^{*}=\frac{2}{3} \frac{1}{P} \frac{\hat{R}_{r}}{\left|\hat{\lambda}_{r}\right|^{2}} T_{e}^{*}
$$

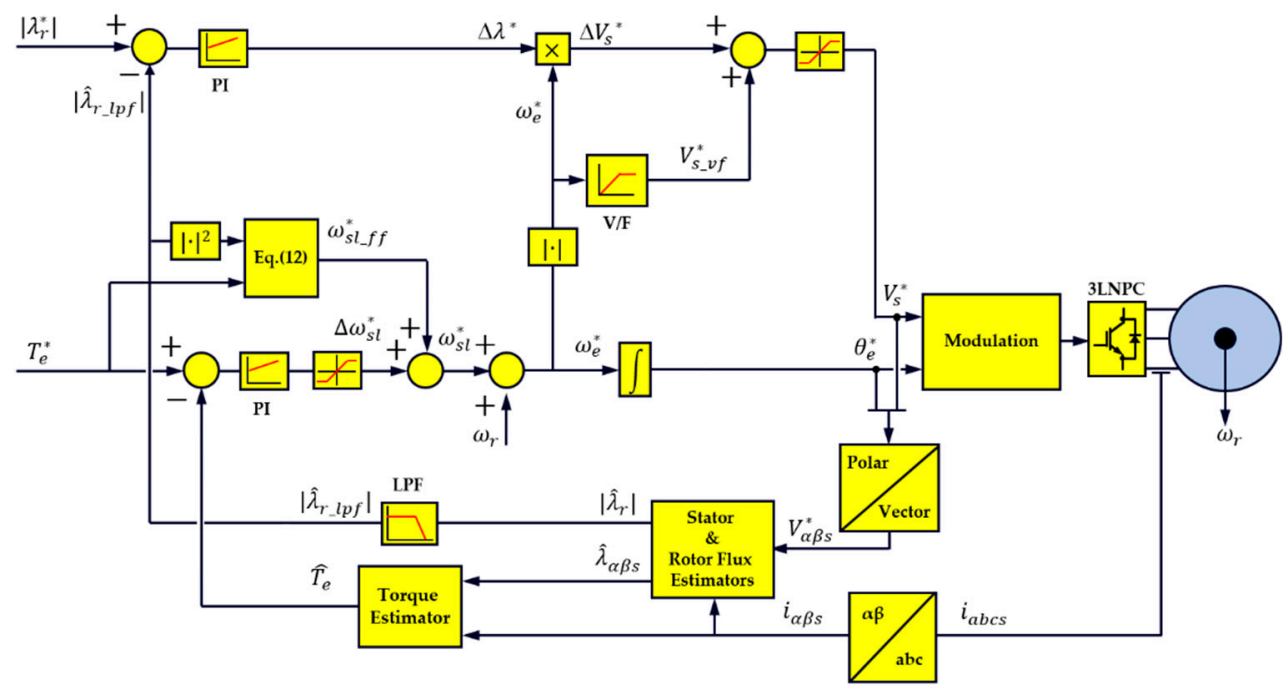

Figure 7. Closed-loop V/F with torque/flux control (CLVFC) scheme.

Due to the fact that the voltage command magnitude and phase angle are independently controlled, flux and torque controllers must be tuned for relatively low bandwidths. A dynamic response eventually 
relies on the accuracy of the feedforward terms. As for the scheme in Figure 6, the scheme in Figure 7 can easily operate in the field-weakening region, including that of six-step.

An alternative approach for the implementation of the feedforward action is to use the machine $d-q$ model in the rotor flux reference frame. The desired $d$ - and q-axis currents are first obtained from the commanded torque and rotor flux using (7) and (8) (see Figure 8). The d- and q-axis stator voltages required to achieve the desired currents are the middle terms in (13), which are obtained from (6).

$$
\left.\begin{array}{l}
v_{d s_{-} f f}^{*}=\hat{R}_{s} i_{d s}^{*}+\hat{\sigma} \hat{L}_{s} p i_{d s}^{*}-\omega_{e}^{*} \hat{\sigma} \hat{L}_{s} i_{q s}^{*}+\frac{\hat{L}_{m}}{\hat{L}_{r}} p \lambda_{d r}^{*} \cong-\omega_{e}^{*} \hat{\sigma} \hat{L}_{s} i_{q s}^{*} \\
v_{q s_{-} f f}^{*}=\hat{R}_{s} i_{q s}^{*}+\hat{\sigma} \hat{L}_{s} p i_{q s}^{*}+\omega_{e}^{*} \hat{\sigma} \hat{L}_{s} i_{d s}^{*}+\omega_{e}^{*} \hat{L}_{m} \lambda_{d r}^{*} \cong \omega_{e}^{*} \hat{\sigma} \hat{L}_{s} i_{d s}^{*}+\omega_{e}^{*} \hat{L}_{m} \lambda_{d r}^{*} \lambda_{d r}^{*}
\end{array}\right\}
$$

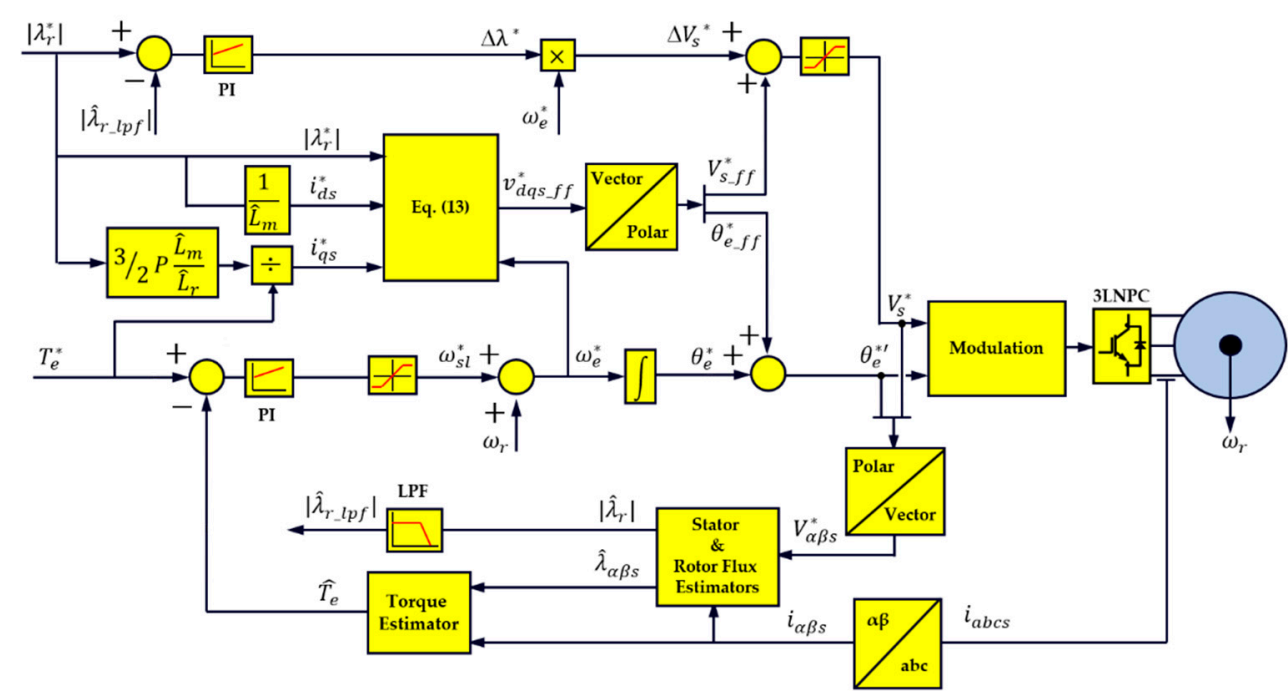

Figure 8. Closed loop V/F with torque/flux control and feedforward (CLVFC\&FF) scheme.

Ideally, (13) will produce the voltage needed to obtain the desired torque and rotor flux with no error. However, there are a number of issues to consider. Mismatch between model and actual parameters must be expected and will produce errors in the feedforward voltages. In addition, (13) includes derivatives which are problematic in practice. It is noted, however, that the signals affected by the derivative (13) are (clean) commanded variables, i.e., do not involve (noisy) measured variables. Furthermore, the torque derivative will be limited by the application, meaning that the derivative of q-axis current and flux commands will be limited too. Finally, the terms depending on the stator resistance will have a reduced weight considering that the control is only intended to operate at a high speed. Based on the previous considerations, the feedforward voltage can be safely simplified to form the right hand of (13). The resulting block diagram is shown in Figure 8, with the feedforward term being either the complete or simplified voltage equation in (13).

\subsection{Vector-Based Control}

Vector control methods are aimed at directly manipulating the IM fields and torque. These methods are based on well-known $d-q$ models. Field-Oriented Control (FOC) represents flux and torque as a function of stator currents in a synchronous reference frame, with high-bandwidth current regulators being used to provide the voltage command to the inverter. Alternatively, Direct Torque Control (DTC) methods implement torque and flux controllers which directly provide the IGBT gate signals for the inverter, i.e., without the explicit control of stator currents. 


\subsubsection{Rotor Field-Oriented Control (RFOC)}

RFOC (see Figure 9) is one of the most popular options for the high-performance control of IM drives [14,15], although its discussion is beyond the scope of this paper. RFOC is often used in HST at relatively low speeds, the inverter operates in the linear region and with an adequate switching to fundamental frequency ratio. However, its use at high speeds presents multiple problems, including the lack of a voltage margin in the inverter for proper operation of the current regulator, distortions in the currents due to overmodulation, and delays intrinsic to the reduced switching frequency. The modification of RFOC to enable operation at the voltage limit was discussed in [16].

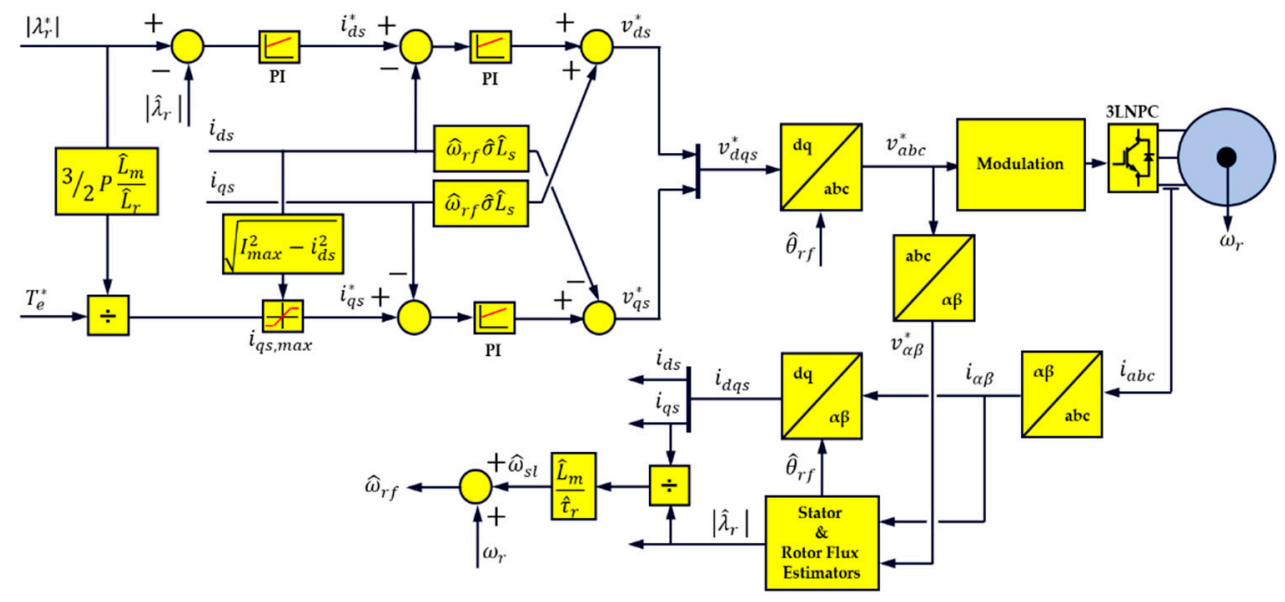

Figure 9. Rotor field-oriented control (RFOC) scheme.

\subsubsection{Direct Flux Vector Control (DFVC)}

DFVC [17] is a stator-flux-oriented control approach. By writing the voltage Equation (1) in stator flux, reference frame (14) can be obtained. It can be observed from (14) that the stator flux variation can be regulated through the $\mathrm{d}$-axis voltage, and the torque is then controlled through the q-axis current (15), with a current regulator being used for this purpose. The DFVC scheme is shown in Figure 10.

$$
\left.\begin{array}{c}
v_{d s}=\hat{R}_{s} i_{d s}+p \hat{\lambda}_{d s} \\
v_{q s}=\hat{R}_{s} i_{q s}+\hat{\omega}_{s f} \hat{\lambda}_{d s}
\end{array}\right\}
$$

Stator flux $\alpha \beta$-components are estimated from the voltage-model-based flux estimator. The synchronous frequency can be obtained from the estimated stator flux and back-emf (16) [18], avoiding the use of stator flux angle derivative and time-consuming trigonometric functions.

$$
\hat{\omega}_{s f}=p \hat{\theta}_{s f}=\frac{d}{d t}\left[\tan ^{-1}\left(\frac{\hat{\lambda}_{\beta s}}{\hat{\lambda}_{\alpha s}}\right)\right]=\frac{\hat{\lambda}_{\alpha s} \cdot \hat{e}_{\beta s}-\hat{\lambda}_{\beta s} \cdot \hat{e}_{\alpha s}}{\left|\hat{\lambda}_{s}\right|^{2}}
$$

At low speeds, DFVC can operate either with rated stator flux or a maximum torque per ampere (MTPA) strategy to improve the efficiency. Above the base speed, flux is reduced according to (17), where $V_{\max }$ is the maximum output voltage of the inverter, which depends on the available DC-link voltage and the modulation method. Operation in overmodulation is feasible, but a voltage margin must be preserved for proper operation of the q-axis current regulator, meaning that operation with a maximum output voltage (i.e., six-step) is not possible. Furthermore, operation in overmodulation 
forces a reduction of the current regulator bandwidth to mitigate the effects of the resulting current harmonics in this case. Therefore, current regulator gains may need to be adapted with machine speeds.

$$
\lambda_{s}^{*} \leq \frac{V_{\max }-\hat{R}_{s} i_{q s}}{\left|\hat{\omega}_{s f}\right|}
$$

It is finally noted that Figure 10 includes a mechanism to limit the torque angle $\delta$ between the stator and rotor fluxes so that it is smaller than the pull-out torque angle of $\delta=45$ electrical degrees [17].

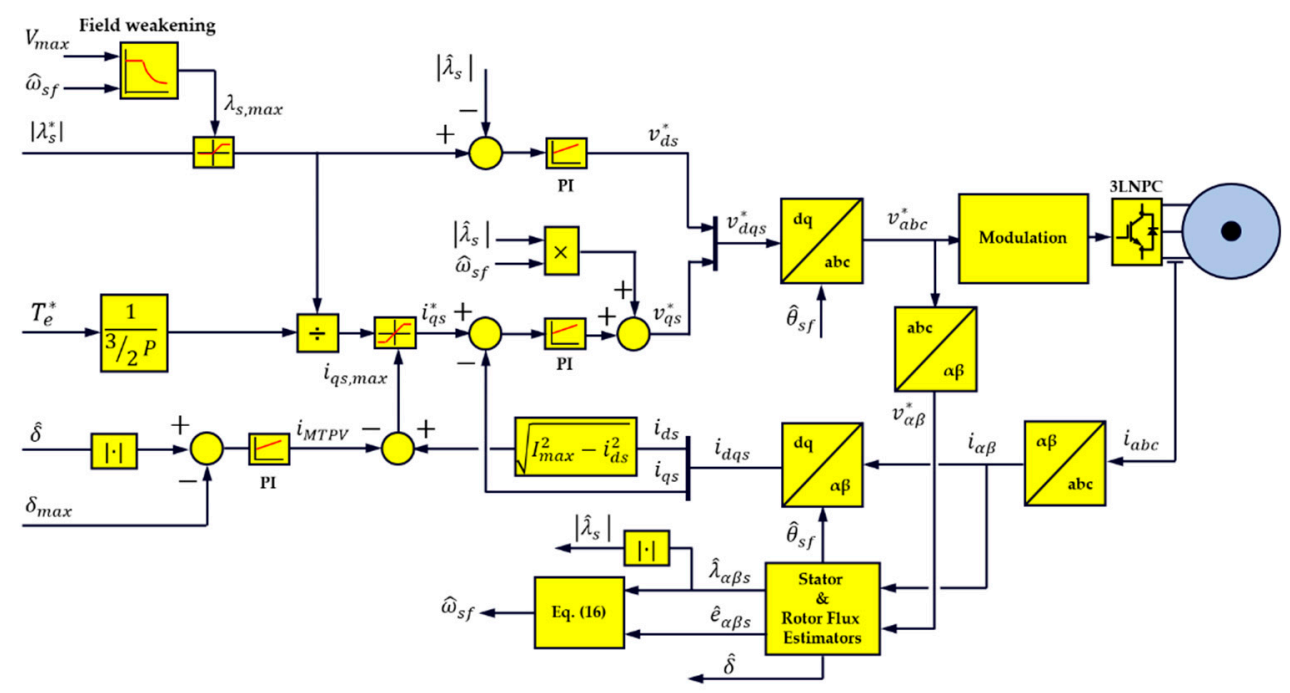

Figure 10. Direct Flux Vector Control (DFVC) scheme.

\subsubsection{Direct Torque Control (DTC)}

IM torque can be expressed as (18), with $\delta$ being the torque angle. DTC methods control torque by controlling the stator flux magnitude and angle with respect to rotor flux. Stator flux is controlled through the stator voltage (19) (stator resistance neglected), with $V_{s}$ being the inverter output voltage vector.

$$
\begin{gathered}
T_{e}=\frac{L_{m}}{\sigma L_{s} L_{r}} \lambda_{s} \lambda_{r} \sin (\delta) \\
\lambda_{s}=\int V_{s} d t
\end{gathered}
$$

Switching-Table-Based (ST-DTC) was introduced by Takahashi and Noguchi [19] in the mid-1980s. Two hysteresis controllers are used to control the stator flux and torque directly. The hysteresis control signals are sent to a look-up table to select the voltage vectors required to achieve high dynamics (see Figure 11). The fact that the switching frequency is not defined and operation in overmodulation and six-step is not straightforward makes this method inadequate for high-power railway drives [20].

Direct-Self Control (DSC) was proposed by Depenbrock [21] for high-power drives. Three hysteresis controllers determine the voltage applied to the machine by comparing a flux magnitude command with the estimated flux for each phase, and a two-level hysteresis torque controller determines the amount of zero voltage (see Figure 12). DSC produces a hexagonal stator flux trajectory, which enables a smooth transition into overmodulation and eventually six-step. However, hexagonal flux trajectories make DSC problematic below $\approx 30 \%$ of the base speed, and remedial actions can be found in $[22,23]$. 


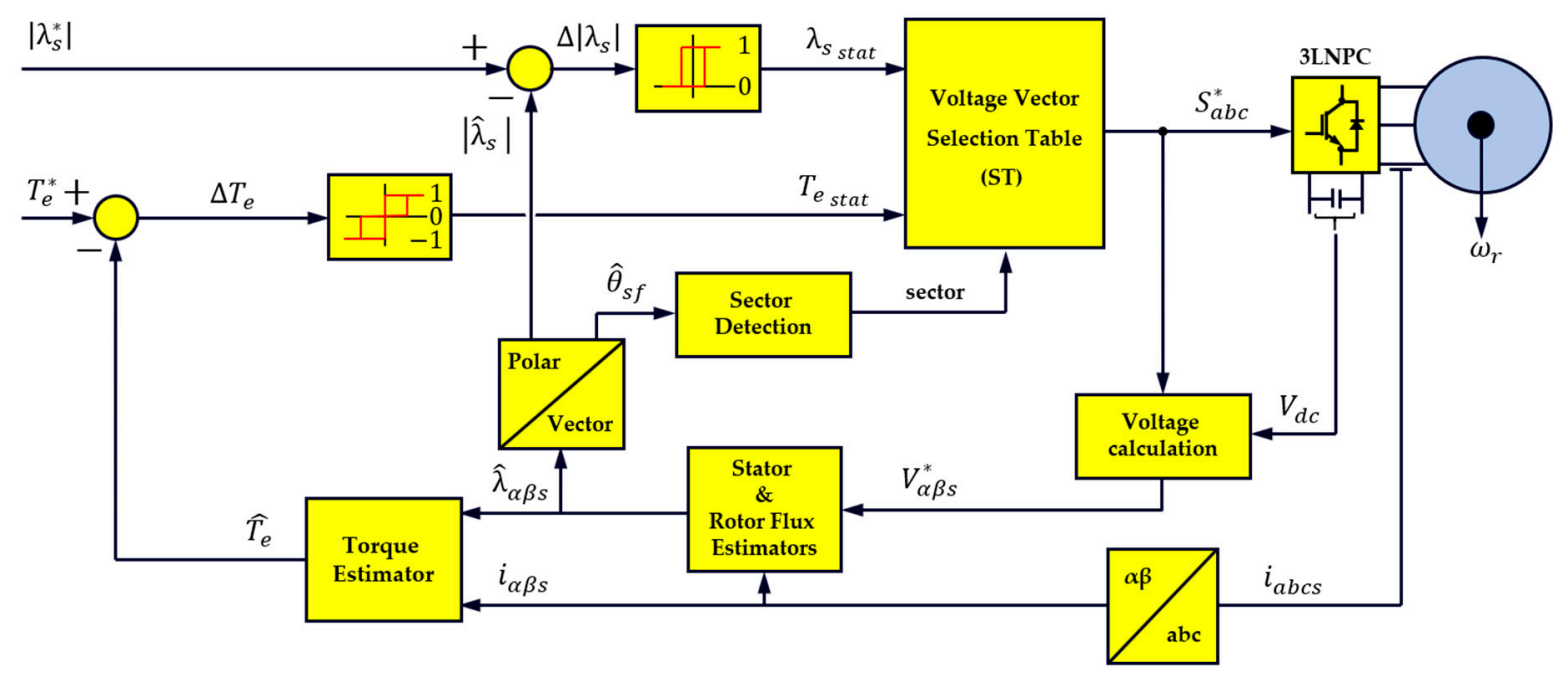

Figure 11. Switching-Table-Based Direct Torque Control (ST-DTC) scheme.

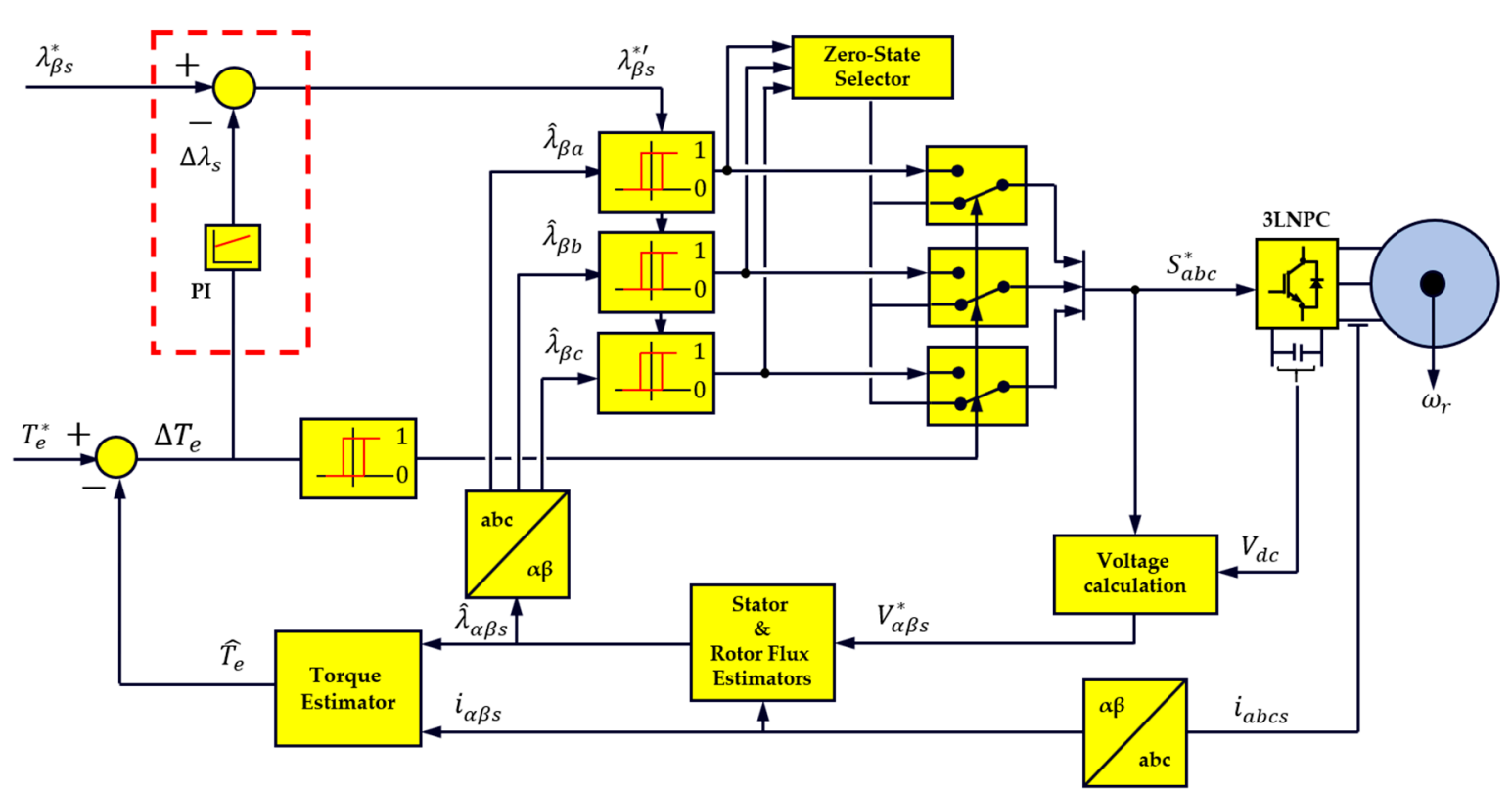

Figure 12. Direct-Self Control (DSC) scheme.

Several modifications have been proposed to overcome the limitations of DTC methods [24]. DTC with a constant switching frequency calculates the required stator voltage vector over a sampling period to achieve the desired torque and stator flux. The voltage vector is synthesized using Space-Vector Modulation (SVM), and these methods are often referred to as DTC-SVM. In the implementation in Figure 13, a PI controls the torque through the torque angle [25]. The stator flux angle is obtained from the estimated rotor flux angle and the commanded torque angle. The stator voltage vector command $V_{\alpha \beta s}^{*}$ employed to cancel the stator flux error $\Delta \lambda_{\alpha \beta s}^{*}$ at the end of the next sampling period $\Delta t$ is obtained as:

$$
V_{\alpha \beta s}^{*}=\frac{\Delta \lambda_{\alpha \beta s}^{*}}{\Delta t}+\hat{R}_{s} i_{\alpha \beta s}
$$




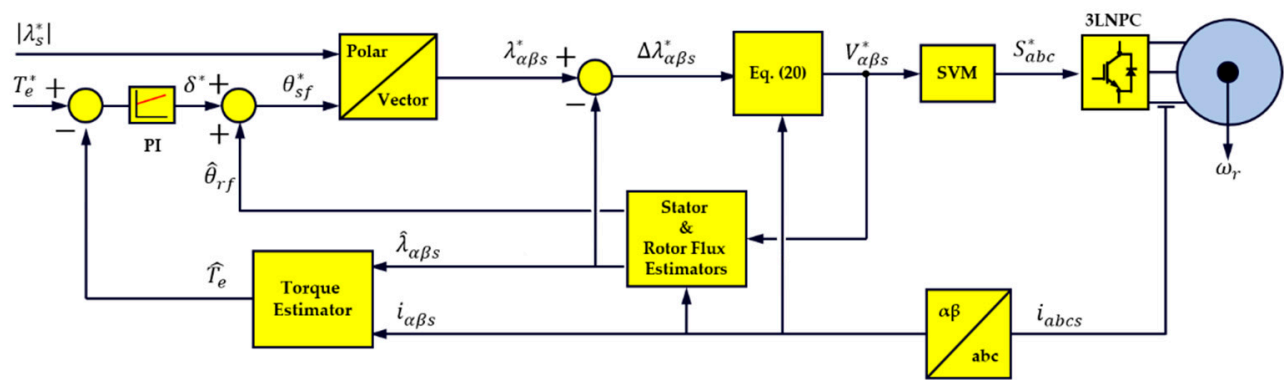

Figure 13. Direct-Torque Control Space-Vector Modulation (DTC-SVM) block diagram.

The scheme in Figure 13 is easy to implement and retains the fast dynamics of DTC if the inverter operates in the linear region. However, voltage distortions intrinsic to overmodulation can result in magnitude and phase deviations of the actual stator flux vector, leading to instability problems. Furthermore, (20) effectively cancels the flux error for relatively small values of $\Delta t$, but can result in large steady-state errors in the case of low switching frequencies. DTC-SVM suffers from the same limitation as ST-DTC when operating in overmodulation and six-step, which raises concerns on their use for high-power, high-speed railway traction drives. A predictive term for mitigating the stator flux delay and extending the operation to six-step was proposed in [26]. However, this was at the price of a significant complexity increase.

\subsection{Control Strategies Summary}

Table 1 summarizes the main conclusions for the control methods discussed in this section, including controlled variables and the easiness of operation at low speeds, overmodulation (high speed), and the transition to six-step. Regarding the dynamic response, it is important to note that the torque ramp is normally limited in railway traction. Consequently, not only the maximum dynamic response (e.g., the minimum time required to respond to a step-like torque command) is relevant, but also the capability of the drive to meet the maximum torque ramp requested by the application, especially when the machine operates at a high speed in the field-weakening region. CLVFC, CLVFVC\&FF, DFVC, and DTC-SVM have been selected as a representative subset of the methods in Table 1, and their behavior will be analyzed by means of simulation in Section 6 .

Table 1. Summary of the presented control schemes for traction applications.

\begin{tabular}{|c|c|c|c|c|c|c|c|c|}
\hline $\begin{array}{l}\text { Properties/ } \\
\text { Performance }\end{array}$ & \multicolumn{3}{|c|}{ V/Hz with Feedback } & \multicolumn{2}{|c|}{ FOC } & \multicolumn{3}{|c|}{ DTC } \\
\hline Controlled variables & $\omega_{r}{ }^{\dagger}$ & $\lambda_{r} ; T_{e}$ & $\lambda_{r} ; T_{e}$ & $\lambda_{r} \& i_{d s} ; i_{q s}$ & $\lambda_{s} ; i_{q s}$ & $\lambda_{s} ; T_{e}$ & $\lambda_{s} ; T_{e}$ & $\lambda_{s} ; T_{e}$ \\
\hline $\begin{array}{c}\text { Defined } \\
\text { switching frequency }\end{array}$ & Yes & Yes & Yes & Yes & Yes & No & No & Yes \\
\hline $\begin{array}{l}\text { Low speed } \\
\text { (linear mod.) }\end{array}$ & $\checkmark$ & $\checkmark$ & $\checkmark$ & $\checkmark$ & $\checkmark$ & $x$ & $x$ & $\checkmark$ \\
\hline $\begin{array}{c}\text { High speed } \\
\text { (overmodulation) }\end{array}$ & $\checkmark$ & $\checkmark$ & $\checkmark$ & - & - & $x$ & $\checkmark$ & $x$ \\
\hline Six-step operation & $\checkmark$ & $\checkmark$ & $\checkmark$ & $x$ & $x$ & $x$ & $\checkmark$ & $x$ \\
\hline
\end{tabular}

$\boldsymbol{V}$ : favorable; - : neutral; $\boldsymbol{x}$ : unfavorable; "SRF" stands for stationary reference frame. ${ }^{\dagger}$ : Implementation of an outer speed control loop for the rest of the methods is straightforward. ${ }^{++}$: (1) maximum torque dynamic response/ (2) capability to provide $3 \mathrm{kNm} / \mathrm{s}$ in the overmodulation region. 


\section{Modulation Techniques}

High-power traction drives usually operate with low switching frequencies $(<1 \mathrm{kHz})$ to reduce switching losses. This results in significant current and consequently torque ripples, which can have implications for mechanical transmission stress, train comfort, standards compliance, etc. Trading-off switching losses and torque pulsations is a challenge for the selection of modulation methods. Furthermore, modulation and control strategies often change with the output frequency. Figure 14 shows an example of this [27]. Asynchronous Pulse-Width Modulation (PWM) is used at low speeds, changing to synchronous modulation with Selective Harmonic Elimination (SHE) and finally single pulse modes as the speed increases. The three options are briefly described in the following, and are particularized for a three-level Neutral-Point-Clamped (3L-NPC) scheme [28], as this is the configuration used in this project.

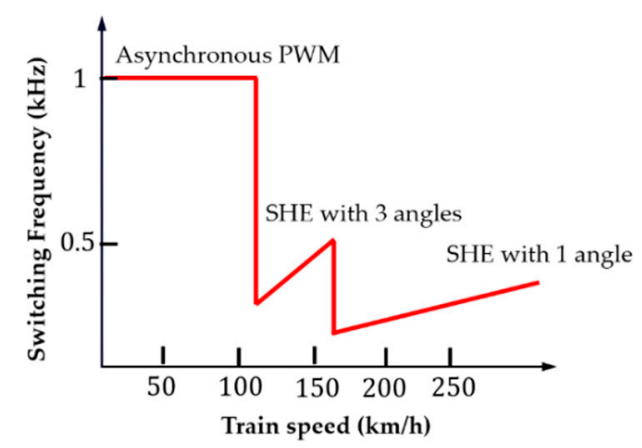

Figure 14. Modulation technique vs. train speed for a High-Speed Train (HST).

\subsection{Asynchronous Modulation}

Carrier-Based Pulse-Width Modulation (PWM) or Space-Vector Modulation (SVM) can be used at low speeds. The first compares the reference voltages $V_{a b c}^{*}$ with two carriers, as shown in Figure 15a. A level-shifted carrier is normally preferred as it results in a lower voltage harmonic content [28]. A common-mode (homopolar) voltage should be added to fully use the available DC link voltage. Space-Vector Modulation (SVM) for three-level inverters shares the same basic principles as that for two-level inverters, but 24 active voltage and three zero vectors are available. The implementation of SVM is shown in Figure 15b. It typically consists of three steps: (1) sector identification, (2) region identification, and (3) the selection of an appropriate switching sequence. Redundant states are used to balance DC link capacitor voltages. SVM offers the same DC voltage utilization as the PWM with a homopolar voltage, and it has a larger computational burden, but makes better use of the redundant states $[29,30]$.

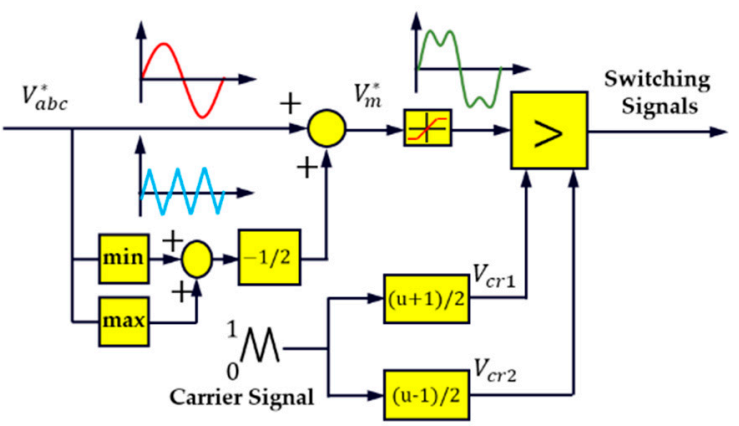

(a)

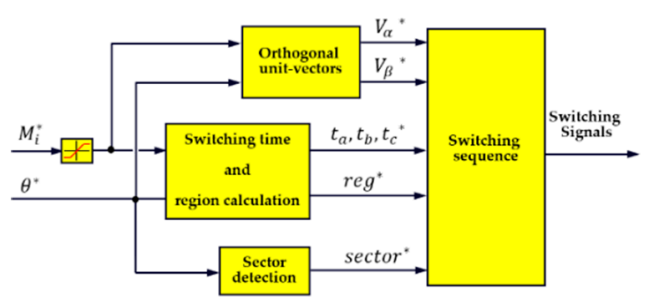

(b)

Figure 15. Asynchronous modulation techniques: (a) Pulse-Width Modulation (PWM) with triple harmonic injection; (b) Space-Vector Modulation (SVM). 


\subsection{Synchronous Modulation-Selective Harmonic Elimination (SHE)}

SHE performs a predefined number of commutations per quarter of the fundamental cycle. Commutations are synchronized with the fundamental wave. Commutation angles are pre-calculated via Fourier analysis [31], with the aim of eliminating specific harmonics of the output voltage. An example of SHE with three switching angles is shown in Figure 16a. With three angles, it is possible to cancel two harmonics of the output voltage (typically the 5th and 7th), in addition to controlling the magnitude of the fundamental voltage. As the speed increases, SHE changes to one pulse mode (Figure 16b) to reduce switching losses. SHE implementation is schematically shown in Figure 16c.

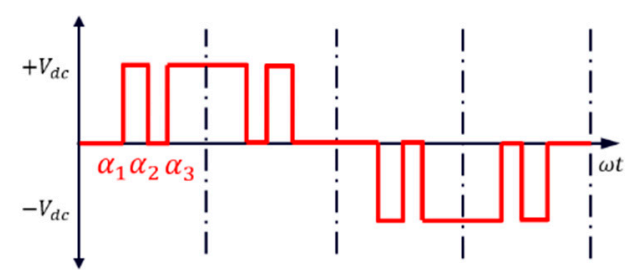

(a)
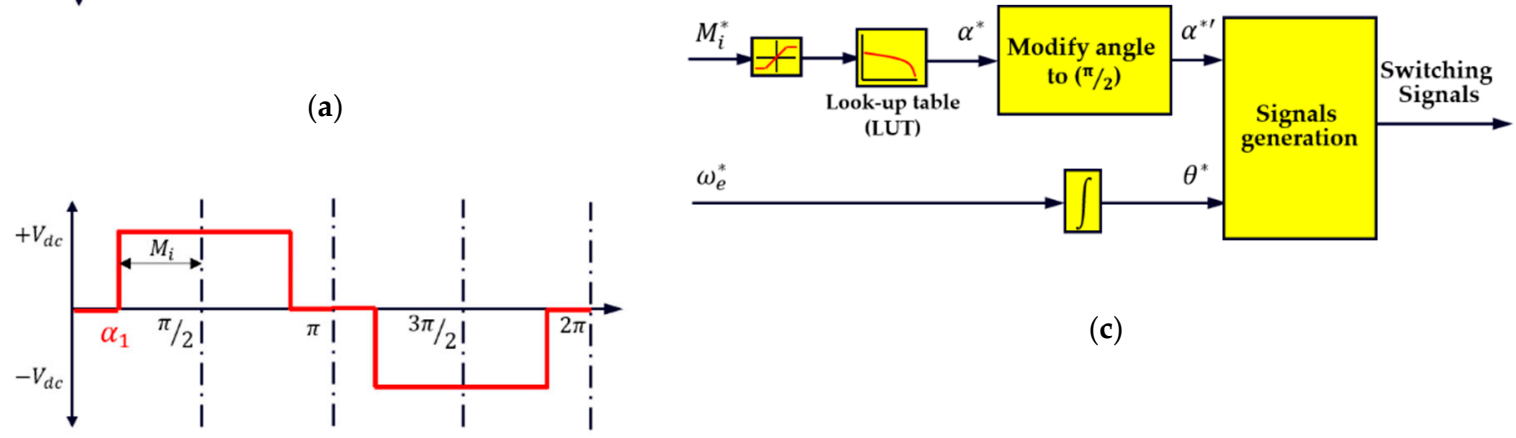

(c)

(b)

Figure 16. Selective Harmonic Elimination (SHE) for three-level Neutral-Point-Clamped (3L-NPC): (a) Phase voltage for the case of three switching angles; (b) phase voltage for the case of one switching angle; (c) Selective Harmonic Elimination (SHE) block diagram.

\section{Operation with Reduced Flux and Remagnetization Strategies}

Electric drives in high-speed traction applications can work for certain periods of time with light loads. It is possible in this case to decrease the flux level to reduce the stator current and consequently Joule losses, which is commonly termed MTPA [32]. However, operating with reduced flux levels will penalize the dynamic response of the drive. If a torque increase is demanded, the machine must be remagnetized first. The remagnetization time is determined by the rotor time constant (7) and applied magnetizing current. Due to the relatively large values of the rotor time constant, fast torque changes of torque are not feasible. It must be noted, however, that fast torque changes are not desirable for traction applications, as they might exert stress on the mechanical transmission, produce wheel slip, and raise comfort concerns. The maximum torque-allowed gradient will depend on the application. For the machine considered in this paper, it has a value of $3 \mathrm{kNm} / \mathrm{s}$.

Figure 17 shows two possible remagnetization strategies. RFOC principles are used for the discussion. It is noted, however, that equivalent strategies can be used with other control methods by simply transforming $d-q$ axis current commands into other commands, e.g., stator flux and slip. 

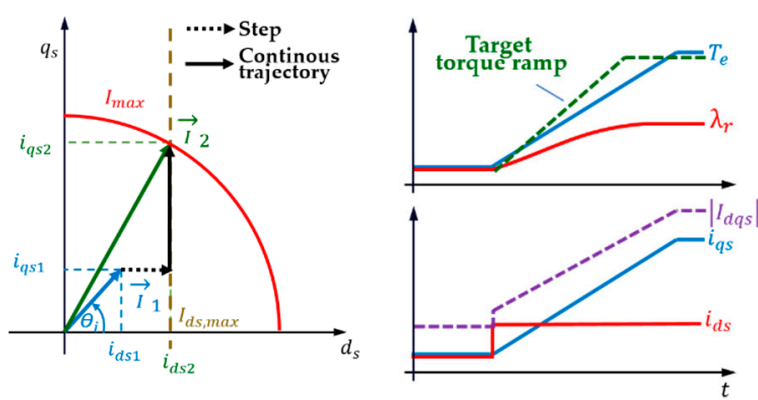

(a) Profile 1: step-like d-axis, ramp-like q axis
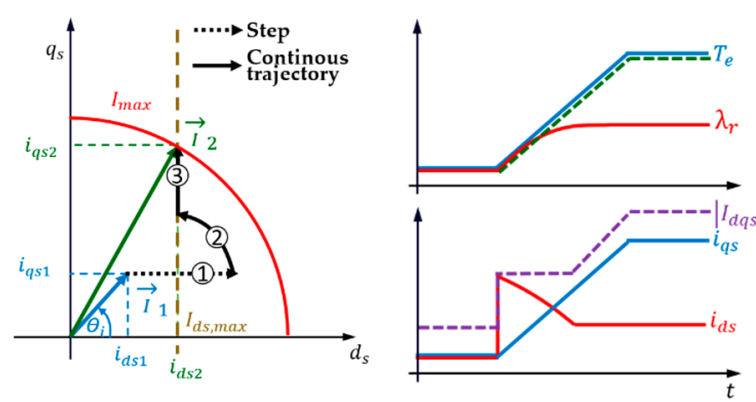

(b) Profile 2: $3 \mathrm{kNm} / \mathrm{s}$ torque ramp, minimum current

Figure 17. Remagnetization (a) using the rated d-axis current and (b) target torque gradient. Left: Current trajectories in the $d-q$ plane; right: torque, rotor flux, and current trajectories vs. time.

The strategy in Figure 14a uses a step-like d-axis current command. While simple, this results in a slow remagnetization, with the $3 \mathrm{kNm} / \mathrm{s}$ target not being achieved. The option in Figure $14 \mathrm{~b}$ is derived from the method described in [33] and is aimed at providing a target torque ramp with the smallest possible current during the remagnetization process. This reduces the stress in the power devices and the risk of surpassing their current limit. This strategy will be used for the simulation results in the next section.

\section{Simulation Results}

Selected control methods from Section 3 have been evaluated by means of simulation using MATLAB/Simulink. IM parameters for the base speed are given in Table 2. The simulation model implements asynchronous SVM with a switching frequency of $1 \mathrm{kHz}$ at low speeds and SHE at high speeds, as shown in Figure 14.

Table 2. Specifications of the induction motor at base speed $\omega_{\text {base }}$ (extended full flux range design).

\begin{tabular}{ccc}
\hline Variable & Value & Unit \\
\hline DC-link voltage & 3600 & $\mathrm{~V}$ \\
Rated Power & 1084 & $\mathrm{~kW}$ \\
Rated Voltage $(\mathrm{L}-\mathrm{L}, \mathrm{rms})$ & 2727 & $\mathrm{~V}$ \\
Pole-pairs $(P)$ & 2 & $\mathrm{Pole}$ \\
Stator resistance $\left(\mathrm{R}_{\mathrm{s}}\right)$ & 55.38 & $\mathrm{~m} \Omega$ \\
Stator inductance $\left(\mathrm{L}_{\mathrm{s}}\right)$ & 26.45 & $\mathrm{mH}$ \\
Torque & 3241 & $\mathrm{Nm}$ \\
Speed & 3194 & $\mathrm{rpm}$ \\
\hline
\end{tabular}

Since the main focus of this paper is high-speed operation, only results at high speed using SHE are provided in this section. Infinite inertia is assumed. Consequently, the rotor speed remained constant throughout the simulation. This assumption is realistic and has no effect on the conclusions. Profile 2 in Figure 17b was used during remagnetization. The maximum torque ramp was limited to $3 \mathrm{kNm} / \mathrm{s}$, which was imposed by the application. Simulation results are shown in Figure 18.

The most remarkable difference is the slowest transient response of CLVFC due to dynamic limitations intrinsic to scalar control. The dynamic response is seen to improve and be comparable to the other methods when the feedforward defined by (13) is used (CLVFC\&FF in Figure 18b).

DFVC and DTC-SVM are seen to provide similar dynamic responses to CLVFC\&FF. Regarding DFVC, it must be noted that to achieve proper operation in the overmodulation region, the q-axis current regulator bandwidth was reduced in the range of ten times to avoid a current regulator reaction to low-order current harmonics due to the non-linear operation of the inverter. The need to dynamically adapt the gains of the current regulator in the high-speed region is an obvious concern. 
It can be observed that DTC-SVM suffers from a steady-state error in the controlled flux due to the low sampling frequency $(\Delta t)$ when SHE is used in the inverter. This results in an increase in the load angle. This could lead to overcurrent or instability if the load angle is not monitored.

Figure 19 summarizes the performance in a steady state for the four control methods, i.e., once the machine is providing its maximum torque. The steady-state error in the flux for DTC-SVM is seen to affect the modulation index and slip. This will eventually affect the machine loss distribution, which is a concern as traction motors can be required to operate close to their thermal limit. CLVFC and CLVFC\&FF are seen to have a higher torque error compared to DFVC, but with little impact on the modulation index and slip. It is noted that a torque error in the range of $1 \%$ is perfectly assumable.
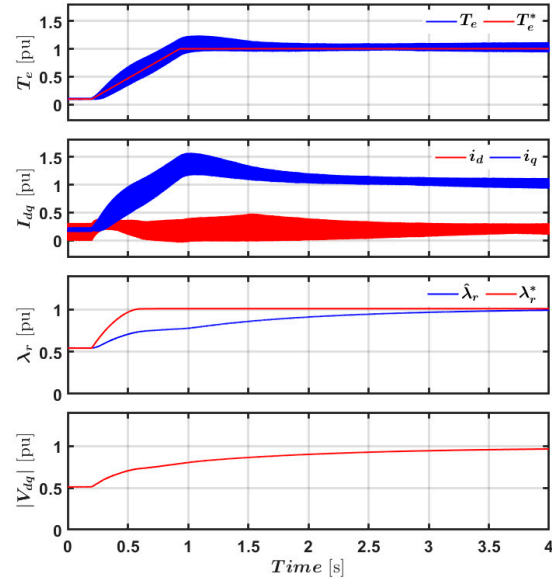

(a)
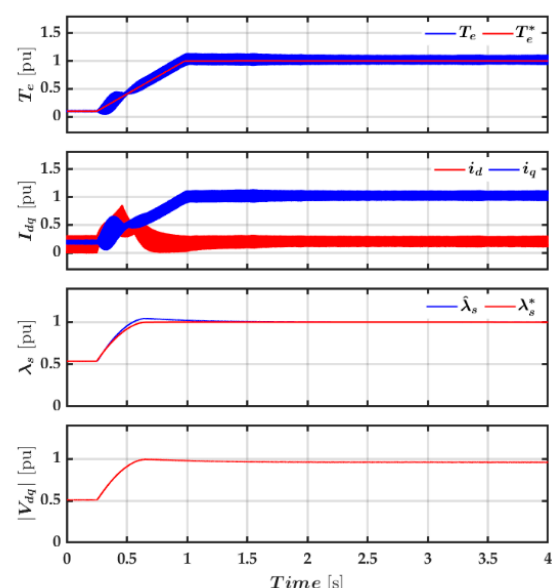

(c)
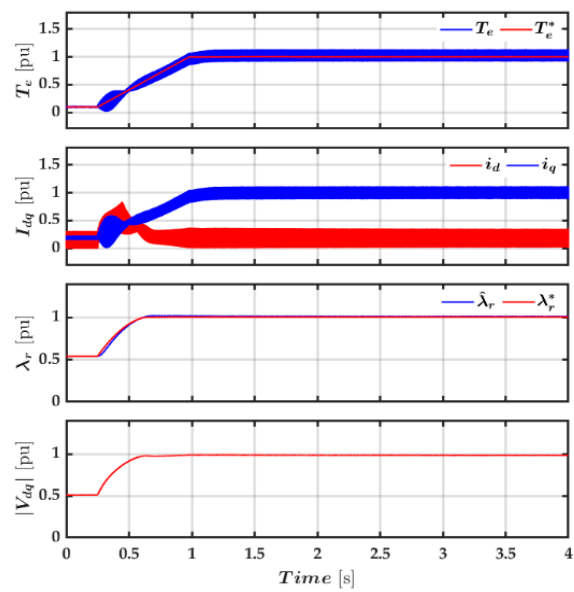

(b)
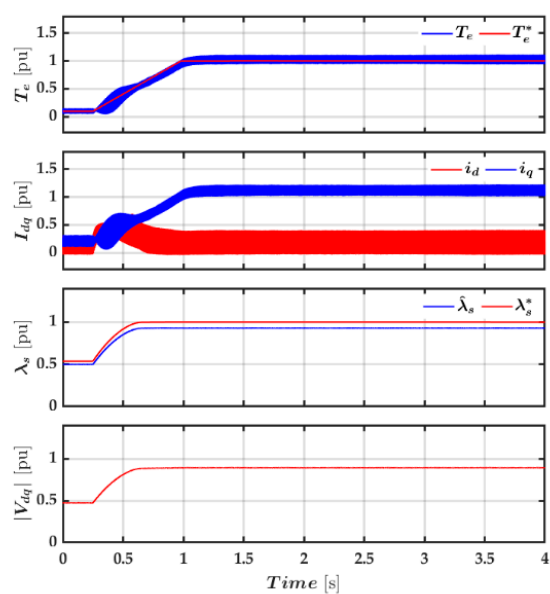

(d)

Figure 18. Simulation results of using (a) CLVFC, (b) CLVFC\&FF, (c) DFVC, and (d) DTC-SVM control methods with SHE. Rotor speed $\omega_{r}=1.328 \omega_{\text {base }}$; torque was increased from $10 \%$ (i.e., with the machine operating with reduced flux in MTPA) to $100 \%$. From top to bottom: commanded and actual torque; $\mathrm{d}$ - and q-axis currents; commanded and estimated flux (can be stator or rotor flux, depending on the method); and output voltage magnitude. All the variables are shown in p.u. 


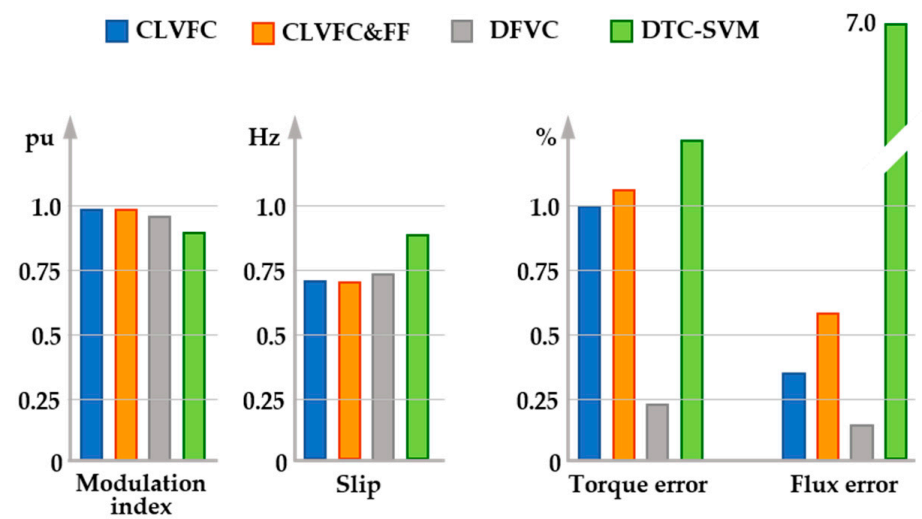

Figure 19. From left to right: modulation index, slip, torque error, and error in the flux being controlled for the four control methods being considered, once the machine has reached a steady state, i.e., is its maximum torque. Torque and slip have been low-pass filtered to eliminate the harmonic content produced by SHE modulation.

It can be concluded that CLVFC\&FF is more adequate compared to the simulated schemes at high speeds due to its high dynamics, and the controllers are not affected by low-order harmonics resulting from a square-wave operation, i.e., six-step, as in the case of DFVC, and are simple to implement.

\section{Experimental Results}

A schematic diagram of the high-power traction system test bench is shown in Figure 20a. It consists of two identical IMs and converters connected back-to-back, which are supplied from a High-Voltage (HV) DC power supply. The power converter module (see Figure 20b) consists of a three-phase, three-level Neutral-Point Clamped (NPC) inverter feeding the IMs. Single-phase inverters feed auxiliary loads, such as cooling systems, control power supply units, etc. A DC-DC chopper is implemented for dissipative braking and DC bus overvoltage protection. A specially designed traction transformer is used to filter off catenary harmonics and allow the interconnection of the different converters. A $100 \mathrm{~Hz}$ (2f) filter is included in the DC bus. The overall experimental test rig is shown in Figure 20c. 


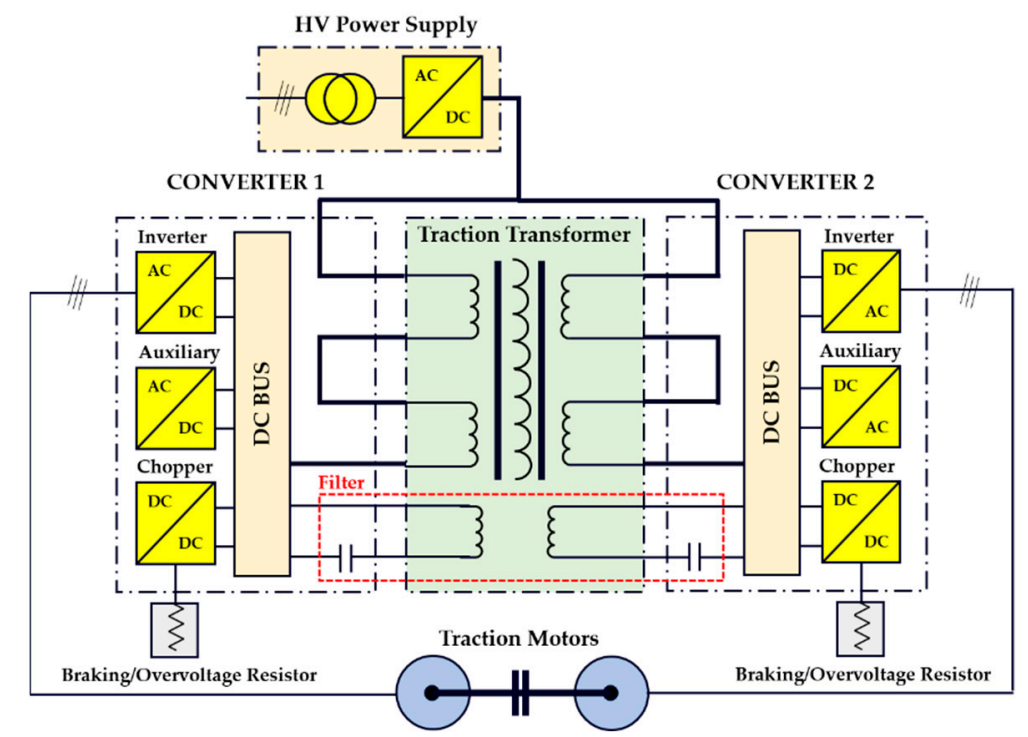

(a)

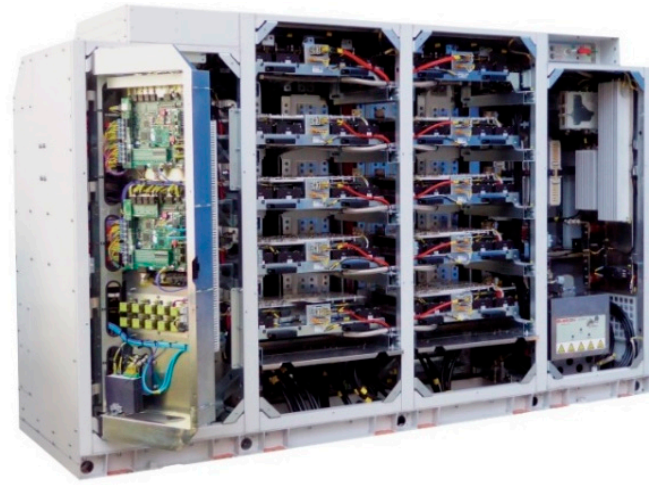

(b)

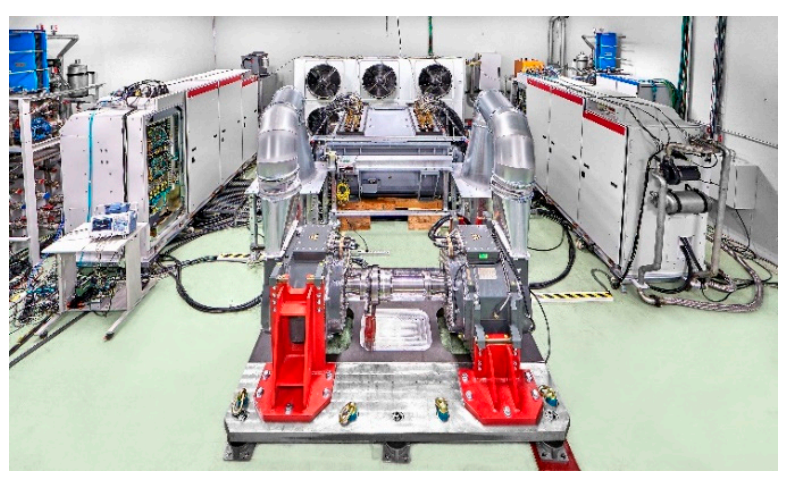

(c)

Figure 20. High-power traction test bench: (a) Schematic diagram; (b) power converter module (INGETRAC); and (c) overall view of the laboratory setup.

Preliminary experimental results for a full-scale HS traction drive are presented in the following. The control uses RFOC at low speeds and CLVFC at high speeds. The main system parameters are the same as those used in the simulation shown in Table 2. The torque-flux characteristic of the motor is of the type named as the extended full flux range in Figure 3.

Figure 21a shows the rotor speed, modulation index, commanded and estimated torques, estimated rotor flux, and magnitude of the stator current vector during an acceleration (left) and deceleration (right) process. Figure 21b shows the spectrogram of the stator current vector. For $\omega_{r}<0.12$ p.u., RFOC-SVM with a switching frequency of $850 \mathrm{~Hz}$ is used; the switching frequency increases to $1 \mathrm{kHz}$ for $0.12<\omega_{r}<0.94$ p.u. For $\omega_{r}>0.94$ p.u., CLVFC combined with SHE with one switching angle is used. Changes in the modulation method are readily observable in the spectrogram of Figure 21b, and are aim to trade-off switching losses and torque ripple. The control is seen to precisely follow the commanded torque and rotor flux in the whole speed range. It is noted that the changes in the estimated rotor flux observed in the flux-weakening region respond to changes in the corresponding command (not shown in the figure). Transitions between the different control and modulation strategies can be a challenge due to the high power and low switching frequencies. However, as can be observed from Figure 21, such transitions are satisfactory, i.e., the spikes observed in the currents are perfectly acceptable and do not represent a risk for the power devices. Implementation of the other control methods and remagnetization strategies discussed in Sections 3 and 6 is ongoing. 

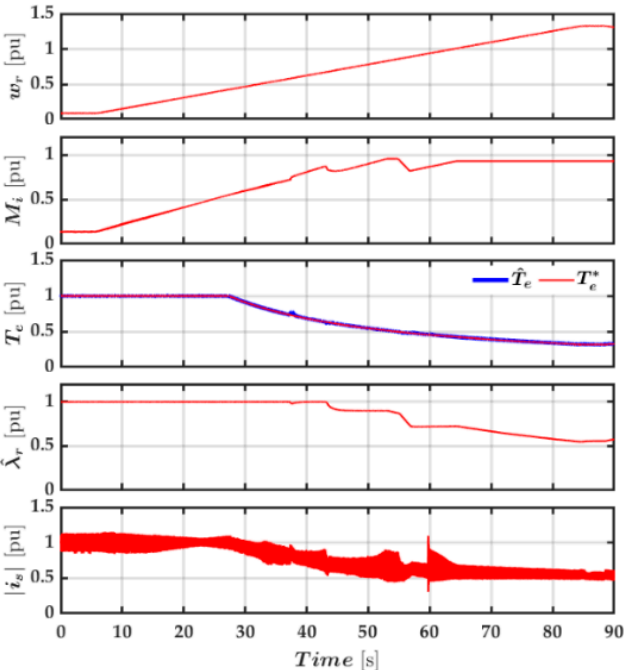

(a)
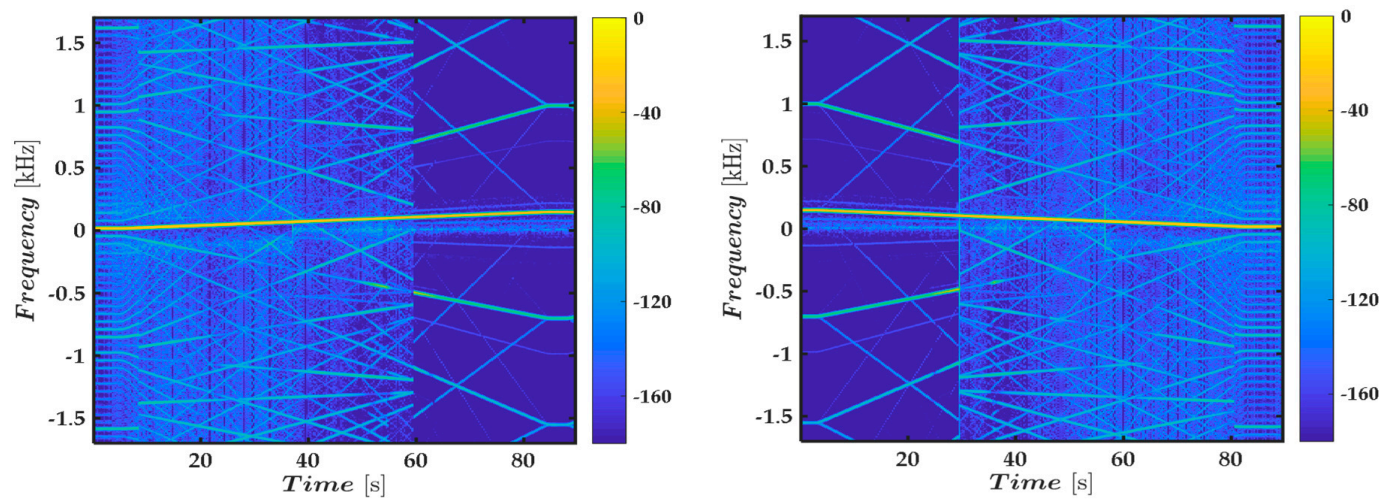

(b)

Figure 21. Experimental results. Acceleration (left)-deceleration (right) tests between $\omega_{r}=0.1$ and $\omega_{r}=1.328$ p.u. (a) From top to bottom: rotor speed, modulation index, commanded and estimated torques, estimated rotor flux, and magnitude of the stator current vector; (b) stator current vector spectrogram.

\section{Conclusions}

In this paper, a comparative analysis of scalar and vector control strategies for railway traction applications has been presented, with a special focus on their operation at high speeds.

HSTs normally use medium-voltage, high-power IMs. Rotor flux Oriented Control (RFOC) has been widely adopted at low and medium speeds. However, high fundamental frequencies intrinsic to high-speed operations, combined with the need to reduce inverter losses, force the inverter to operate with reduced switching frequencies and a high modulation index or even at the six-step limit. These limitations seriously compromise the performance of RFOC at high speeds. A common practice is to use RFOC at low speeds, rather than switch to strategies able to perform properly under severe voltage constraints at high speeds.

Methods considered for the analysis included different types of Closed-loop Voltage/Frequency (V/F), Field-Oriented Control (FOC), and Direct-Torque Control (DTC) strategies. Four different control strategies have been selected and tested by means of simulation, namely, Closed Loop V/F with flux/torque Control (CLVFC), CLVFC with feedforward (CLVFC\&FF), Direct Flux Vector Control (DFVC), and Direct-Torque Control Space-Vector Modulation (DTC-SVM). The modulation methods that have been considered are PWM/SVM, SHE, and six-step. Their advantages include the easiness 
of operation with a high modulation index, including six-step; switching frequency; and dynamic response to both torque change demands and rotor flux change demands during remagntization.

The CLVFC\&FF method described in Section 3.1.3 and the remagnetization strategy discussed in Section 5 are the original contributions of this paper.

It was concluded from the simulation results that CLVFC, CLVFC\&FF, and DFVC provide similar performances. However, DFVC requires a modification of the q-axis current controller gains when the drive enters the overmodulation region. Specifically, CLVFC\&FF proposed in this paper operates properly with a high modulation index, including six-step, and provides a good dynamic response during remagnetization.

Preliminary experimental results using CLVFC in a full-scale traction drive have been provided, which are in good agreement with the simulation results, and confirm the viability of this strategy. Implementation of the other strategies, including remagnetization, is ongoing.

Author Contributions: Conceptualization, F.B. and D.O.; methodology, F.B., J.M.G. and D.O.; formal analysis, A.F.A., J.M.G. and F.B.; simulation and programing, A.F.A., A.E. and I.M.; validation, A.F.A., A.E. and I.M.; writing-original draft preparation, A.F.A.; writing-review and editing F.B. and J.M.G.; supervision, F.B., D.O. and I.L.; All authors have read and agreed to the published version of the manuscript.

Funding: This research was funded by the European Commission H2020 under grant UE-18-POWER2POWER-826417; The Spanish Ministry of Science, Innovation and Universities under grant MCIU-19-PCI2019-103490; and by the Government of Asturias under grant IDI/2018/000188 and FEDER funds.

Conflicts of Interest: The authors declare no conflict of interest.

\section{References}

1. Nikolas Hill, E.K. 2019 Government Greenhouse Gas Conversion Factors for Company Reporting: Methodology Paper for Emission Factors Final; Government UK: London, UK, 2019.

2. Hill, R.J. Electric railway traction. Part 2: Traction drives with three-phase induction motors. Power Eng. J. 1994, 8, 143-152. [CrossRef]

3. El-Refaie, A.M. Motors/generators for traction/propulsion applications: A review. IEEE Veh. Technol. Mag. 2013, 8, 90-99. [CrossRef]

4. Buyukdegirmenci, V.T.; Bazzi, A.M.; Krein, P.T. Evaluation of induction and permanent-magnet synchronous machines using drive-cycle energy and loss minimization in traction applications. IEEE Trans. Ind. Appl. 2014, 50, 395-403. [CrossRef]

5. Ronanki, D.; Singh, S.A.; Williamson, S.S. Comprehensive Topological Overview of Rolling Stock Architectures and Recent Trends in Electric Railway Traction Systems. IEEE Trans. Transp. Electrif. 2017, 3, $724-738$. [CrossRef]

6. McGean, T.J. Developing IEEE rail transit vehicle standards. In Proceedings of the 1998 ASME/IEEE Joint Railroad Conference, Philadelphia, PA, USA, 16 April 1998; pp. 95-105.

7. Drofenik, U.; Canales, F. European trends and technologies in traction. In Proceedings of the 2014 International Power Electronics Conference IPEC-Hiroshima-ECCE Asia, Hiroshima, Japan, 18-21 May 2014; pp. 1043-1049.

8. Sato, K.; Yoshizawa, M.; Fukushima, T. Traction systems using power electronics for Shinkansen High-speed Electric Multiple Units. In Proceedings of the 2010 International Power Electronics Conference IPEC-ECCE Asia, Sapporo, Japan, 21-24 June 2010; pp. 2859-2866.

9. Krause, P.C.; Thomas, C.H. Simulation of Symmetrical Induction Machinery. IEEE Trans. Power Appar. Syst. 1965, 84, 1038-1053. [CrossRef]

10. Ikeda, R.; Yusya, S.; Kondo, K. Study on Design Method for Increasing Power Density of Induction Motors for Electric Railway Vehicle Traction. In Proceedings of the 2019 IEEE International Electric Machines \& Drives Conference (IEMDC), San Diego, CA, USA, 12-15 May 2019; pp. 1545-1550.

11. Buhrkall, L. Traction System Case Study. In Proceedings of the 2008 IET Professional Development Course on Electric Traction Systems, Manchester, UK, 3-7 November 2008; pp. 45-63.

12. Bose, B.K. Modern Power Electronics and AC Drives; Prentice-Hall, Inc.: Upper Saddle River, NJ, USA, 2002. 
13. Holtz, J. Sensorless control of induction machines-With or without signal injection? IEEE Trans. Ind. Electron. 2006, 53, 7-30. [CrossRef]

14. Blaschke, F. The principle of field orientation as applied to the new TRANSVECTOR closed loop control system for rotating field machines. J. Chem. Inf. Model. 1972, 34, 217-220.

15. Kubota, H.; Matsuse, K. Speed sensorless field-oriented control of induction motor with rotor resistance adaptation. IEEE Trans. Ind. Appl. 1994, 30, 1219-1224. [CrossRef]

16. Kwon, Y.-C.; Kim, S.; Sul, S.-K. Six-Step Operation of PMSM With Instantaneous Current Control. IEEE Trans. Ind. Appl. 2014, 50, 2614-2625. [CrossRef]

17. Pellegrino, G.; Bojoi, R.I.; Guglielmi, P. Unified direct-flux vector control for AC motor drives. IEEE Trans. Ind. Appl. 2011, 47, 2093-2102. [CrossRef]

18. Novotny, D.W. Implementation of Direct Stator Flux Orientation Control on a Versatile dsp Based System. IEEE Trans. Ind. Appl. 1991, 27, 694-700.

19. Takahashi, I.; Noguchi, T. A New Quick-Response and High-Efficiency Control Strategy of an Induction Motor. IEEE Trans. Ind. Appl. 1986, IA-22, 820-827. [CrossRef]

20. Casadei, D.; Serra, G.; Stefani, A.; Tani, A.; Zarri, L. DTC drives for wide speed range applications using a robust flux-weakening algorithm. IEEE Trans. Ind. Electron. 2007, 54, 2451-2461. [CrossRef]

21. Depenbrock, M. Direct self-control (DSC) of inverter fed induktion machine. In Proceedings of the 1987 IEEE Power Electronics Specialists Conference, Blacksburg, VA, USA, 21-26 June 1987; pp. 632-641.

22. Steimel, A. Direct self-control and synchronous pulse techniques for high-power traction inverters in comparison. IEEE Trans. Ind. Electron. 2004, 51, 810-820. [CrossRef]

23. Spichartz, M.; Heising, C.; Staudt, V.; Steimel, A. Indirect Stator-Quantities Control as Benchmark for Highly Dynamic Induction Machine Control in the Full Operating Range. In Proceedings of the 14th International Power Electronics and Motion Control Conference EPE-PEMC, Ohrid, Macedonia, 6-8 September 2010; pp. T3-T13.

24. Buja, G.S.; Kazmierkowski, M.P. Direct Torque Control of PWM Inverter-Fed AC Motors-A Survey. IEEE Trans. Ind. Electron. 2004, 51, 744-757. [CrossRef]

25. Rodríguez, J.; Pontt, J.; Silva, C.; Kouro, S.; Miranda, H. A novel direct torque control scheme for induction machines with space vector modulation. In Proceedings of the 2004 IEEE 35th Annual Power Electronics Specialists Conference (IEEE Cat. No.04CH37551), Aachen, Germany, 20-25 June 2004; Volume 2, pp. 1392-1397.

26. Tripathi, A.; Khambadkone, A.M.; Panda, S.K. Stator flux based space-vector modulation and closed loop control of the stator flux vector in overmodulation into six-step mode. IEEE Trans. Power Electron. 2004, 19, 775-782. [CrossRef]

27. Yano, M.; Iwahori, M. Transition from Slip-Frequency Control to Vector Control for Induction Motor Drives of Traction Applications in Japan. In Proceedings of the Fifth International Conference on Power Electronics and Drive Systems, Singapore, 17-20 November 2003; pp. 1246-1251.

28. Rodriguez, J.; Bernet, S.; Steimer, P.K.; Lizama, I.E. A survey on neutral-point-clamped inverters. IEEE Trans. Ind. Electron. 2010, 57, 2219-2230. [CrossRef]

29. Wang, F. Sine-triangle versus space-vector modulation for three-level PWM voltage-source inverters. IEEE Trans. Ind. Appl. 2002, 38, 500-506. [CrossRef]

30. Attique, Q.M. A Survey on Space-Vector Pulse Width Modulation for Multilevel Inverters. CPSS Trans. Power Electron. Appl. 2017, 2, 226-236. [CrossRef]

31. Al-Hitmi, M.; Ahmad, S.; Iqbal, A.; Padmanaban, S.; Ashraf, I. Selective harmonic elimination in awide modulation range using modified Newton-raphson and pattern generation methods for a multilevel inverter. Energies 2018, 11, 458. [CrossRef]

32. Wasynczuk, O.; Sudhoff, S.D.; Corzine, K.A.; Tichenor, J.L.; Krause, P.C.; Hansen, I.G.; Taylor, L.M. A maximum torque per ampere control strategy for induction motor drives. IEEE Trans. Energy Convers. 1998, 13, 163-169. [CrossRef]

33. Popov, A.; Lapshina, V.; Briz, F.; Gulyaev, I. Estimation of the Required Voltage for Improved MTPA Algorithm. In Proceedings of the 2018 X International Conference Electrical Power Drive Systems (ICEPDS), Novocherkassk, Russia, 3-8 October 2018; pp. 1-4. 
(C) 2020 by the authors. Licensee MDPI, Basel, Switzerland. This article is an open access article distributed under the terms and conditions of the Creative Commons Attribution (CC BY) license (http://creativecommons.org/licenses/by/4.0/). 